\title{
Knowledge Sharing Through Face-To-Face Communication and Labour Productivity: Evidence from British Workplace
}

\author{
Sergio Salis ${ }^{1}$ and Allan M. Williams ${ }^{2}$ \\ ${ }^{1}$ Policy Studies Institute and ${ }^{2}$ London Metropolitan University (ISET)
}

July 2008

\begin{abstract}
We investigate whether workplaces adopting human resources management (HRM) practices that enhance face-to-face communication (FTFC) among employees are more productive than workplaces that do not use such arrangements. The underlying rationale is that facilitating employees' physical proximity and verbal interaction makes knowledge sharing within organisations more effective with a subsequent positive effect on labour productivity. We test this hypothesis using data on around 500 British trading establishments from the linked 2004 Workplace Employment Relations Survey and Annual Business Inquiry, for which both measures of value added per employee and information on HRM practices are available. We find a positive association between productivity and FTFC in social networks established through four HRM practices, namely problem-solving groups, teams, meetings made up of senior managers and employees, and meetings of line managers and employees (specifically, this association is found for teams and problem-solving groups involving a moderate percentage of employees at the workplace). However, this result holds only provided that workplaces adopt FTFC on a continuous basis.
\end{abstract}

Keywords: Human resources management, face-to-face communication, knowledge sharing and labour productivity.

JEL Classification: J24, O15

Contact authors: Sergio Salis: Policy Studies Institute, 50 Hanson Street - London W1W 6UP. E-mail: S.Salis@psi.org.uk. Phone: +44 0207911 7506. Allan M. Williams: London Metropolitan University (ISET), 166-220 Holloway Road - London N7 8DB. E-mail: Allan.Williams@,londonmet.ac.uk. Phone: +44 02071332914. 
This paper was financed under the EPSRC research grant $\mathrm{n}$. EP/D01350X/1. The authors are particularly grateful to the WERS 2004 Information and Advice Service team, at the National Institute of Economic and Social Research, especially to John Forth for his constant advice and to Helen Bewley, Alex Bryson and Michael White, at the Policy Studies Institute, for helpful comments. They also thank the Office for National Statistics (ONS) in London, which provided access to the linked 2004 WERS Financial Performance Questionnaire and Annual Business Inquiry. This work contains statistical data from ONS, which is Crown copyright and reproduced with the permission of the controller of HMSO and Queen's Printer for Scotland. The use of the ONS statistical data in this work does not imply the endorsement of the ONS in relation to the interpretation or analysis of the statistical data. This work uses research datasets which may not exactly reproduce National Statistics aggregates. The authors also acknowledge the Department of Trade and Industry, the Economic and Social Research Council, the Advisory, Conciliation and Arbitration Service and the Policy Studies Institute as the originators of the 2004 WERS data, and the Data Archive at the University of Essex as the distributor of the data. The National Centre for Social Research was commissioned to conduct the survey fieldwork on behalf of the sponsors. None of the individuals or organisations mentioned above bear any responsibility for the analysis or interpretations presented here.

\section{INTRODUCTION}

Managing knowledge flows effectively is widely regarded as crucial for organisations that wish to achieve competitive advantage (Dierickx and Cool, 1989; Collins and Clark, 2003). The existing human resources management (HRM) literature acknowledges in general terms that this challenge can be best faced by adopting an HRM archetype characterised by the presence of social networks (Lepak and Snell, 2007). Nonetheless, this literature has not given proper attention to the knowledge construct and, as a consequence, has neglected to analyse empirically the relationship between intra-organisational knowledge sharing and site productivity. This paper attempts to fill this research gap by explicitly focusing on HRM practices that enhance social networks based on face-to-face communication (FTFC), as the knowledge shared within these networks has strong bearings on competitive advantage.

FTFC arises when individuals physically close to each other engage in a mutual exchange of verbal information. Like other communication mechanisms, it allows the exchange of employees' knowledge throughout the organisation. However, exchanging knowledge by means of FTFC is expected to be more effective compared to other means of information sharing. Interactive networks based on the intranet or phone system, for example, are not characterised by employees' physical proximity. One-way communication practices like suggestion schemes, formal surveys of employees and certain other types of information disclosure do not entail verbal interaction among individuals, and in any case result by definition in simple unidirectional knowledge flows (i.e., from the source of knowledge to its recipient). Given their nature, the aforementioned communication mechanisms are expected 
to enhance the exchange of explicit knowledge, i.e. knowledge that can be easily codified, throughout the organisation.

On the other hand, it is widely argued that FTFC is likely to result in the sharing of tacit knowledge (Rebernik and Širec, 2007; Nonaka and Takeuchi, 1995; Koskinen et al., 2003; Meherabian, 1971). As the latter is deeply embedded in its bearers, which are often unaware of possessing it (Polanyi, 1966), physical contact and verbal interaction are crucial requisites for its transfer among individuals. Tacit knowledge is highly idiosyncratic and thus very difficult to imitate (Nonaka, 1991; Grant, 1993; Spender, 1993; Sobol and Lei, 1994; Ambrosini and Bowman, 2001), which makes it a unique source of competitive advantage. While it is arguable that all social networks based on FTFC actually result in the sharing of tacit knowledge, the personalisation and multi-directionality of knowledge flows characterising these networks suggest that this communication mechanism is to be considered as qualitatively superior compared to other means of knowledge exchange.

The above remarks suggest that workplaces that implement HRM practices in such a way as to facilitate FTFC among employees are expected to show a better economic performance compared to workplaces where such arrangements are absent. The main objective of this paper is indeed to investigate whether this expectation is supported by empirical evidence. To this end we use cross-sectional data on around 500 British trading workplaces for which information on HRM practices enhancing FTFC (namely, problem-solving groups, teams, meetings between senior managers and employees, meetings between line managers and employees, and committees of managers and employees' representatives) and account-based measures of labour productivity is available. Information on HRM practices comes from the Management Questionnaire of the 2004 Workplace Employment Relations Survey (WERS), while the measures of value added per employee are drawn from the linked WERS 2004 Financial Performance Questionnaire and Annual Business Inquiry, made available by the Office for National Statistics in London.

This paper contributes to the existing research on the association between HRM practices and labour productivity in several ways. First, it seeks to give serious attention to the concept of knowledge, which has been up-to-now rather neglected by HRM studies and remained in the exclusive domain of the knowledge management literature. Second, by assessing workplaces' productivity gains deriving from knowledge sharing through FTFC it makes a first attempt to draw a distinction between the different communication mechanisms used by organisations to manage their internal knowledge. Finally, this paper is one of the few studies to use objective measures of labour productivity for British workplaces. With few exceptions (namely, Patterson et al. (1997) and Guest et al. (2003)), in fact, the existing HRM studies have relied on subjective measures of labour productivity (e.g. Bryson et al., 2005; Guest and Hoque, 1994; Hoque, 1999; Wood and de Menezes, 1998).

The reminder of the paper is organised as follows. Section 2 explains the importance of FTFC for intra-organisational knowledge sharing, exposes the relevant literature on the association between HRM practices and workplace productivity, and provides a rationale for the conceptualisation of knowledge sharing within this literature. Section 3 describes the data employed. Section 4 presents the empirical results. Finally, Section 5 concludes. 


\section{LITERATURE REVIEW}

\section{1 - Knowledge sharing through FTFC}

The resource-based view of the firm (Barney, 1991) suggests that an organisation can achieve market dominance by combining resources that are rare, valuable and difficult to imitate. Among the many possible resources that an organisation can use for this purpose, knowledge stocks (that is, the knowledge embedded in its workers) is an often cited one (Jackson et al., 2003). Nonetheless, it has been pointed out that while knowledge stocks provide organisations with the foundation for competitive advantage, what really matters is the effective management of knowledge flows (Dierickx and Cool, 1989; Collins and Clark, 2003). This is achievable by workplaces through the establishment of social networks made up of individuals with strong ties and reciprocal trust (Lepak and Snell, 2007). The increasing interest in knowledge sharing through social networks has shifted the research focus from human capital to social capital, the latter being defined as "the sum of the actual and potential resources embedded within, available in, and derived from the network of relationships possessed by an individual or social unit (Nahapiet and Ghoshal, 1998: 243)." This idea is already present in Tsoukas (1996), who views the firm as a 'distributed knowledge system,' where knowledge is embedded in individuals, located in its different parts, and their social interactions.

It is important to note that the knowledge that can be shared within social networks can be explicit or tacit in its nature. Explicit knowledge is that type of knowledge that can be codified and thus communicated easily (Nonaka and Takeuchi, 1995). Interactive networks based on the intranet or phone systems are an example of intra-organisational arrangements enhancing the transfer of explicit knowledge. One-way communication practices like suggestion schemes, formal surveys of employees and information disclosure from employees to managers or from managers to employees are also important means to diffuse explicit knowledge. Tacit knowledge is instead very difficult to formalise and therefore to transfer, since it is deeply embedded in its bearers (Nonaka, 1991). The latter are often unaware of possessing it. As pointed out by Michael Polanyi, who first introduced the concept of tacit knowledge, "we can know more than we can tell (Polanyi, 1966: 4)." Tacit knowledge is being increasingly regarded as the recipe for competitive advantage (Grant, 1993; Spender, 1993; Sobol and Lei, 1994). Given its high level of personalisation, in fact, tacit knowledge can be considered unique, imperfectly mobile/imitable and non-substitutable (Ambrosini and Bowman, 2001) and thus closer than explicit knowledge to the definition of 'resource' required by the resource-based view of the firm.

According to Nonaka (1991) and Sternberg (1994), tacit knowledge is practical (i.e., it describes a process) and context-specific (i.e., it is acquired in situations where it is used). Therefore, it can be better acquired through personal experience and learning by doing in practical situations entailing face-to-face interactions such as coaching, networking and the like (Rebernik and Širec, 2007). According to Nonaka and Takeuchi (1995), personal contact enhances the tacit-to-tacit knowledge exchange. Koskinen et al. (2003) view face-to-face interaction as the richest medium to transfer knowledge, as "it allows immediate feedback so 
that understanding can be checked and interpretation corrected (Koskinen et al., 2003: 286)." This form of interaction is in fact less likely to result in misinterpretation of meanings compared to other forms of social relations, since the knowledge conveyed by body language, facial expression and tone of voice goes beyond the spoken message (Meherabian, 1971).

In conclusion, a large knowledge management literature supports the view that that social networks based on employees' physical contact and dialogue are likely to result in the diffusion of tacit knowledge throughout the organisation. Therefore, we would expect that, other things being equal, workplaces facilitating FTFC among employees enjoy a substantial competitive advantage, in the form of higher productivity, compared to workplaces where this means of knowledge sharing is absent. This proposition is certainly very appealing from a theoretical point of view, but requires some empirical testing.

\section{2 - Empirical evidence on the nexus HRM practices-labour productivity}

A body of industry-specific and cross-industry empirical studies published by American researchers suggests a positive association exists between specific HRM practices, labelled 'high-performance' HRM practices, and organisational productivity in the US (Appelbaum et al., 2000; Arthur, 1994; Batt, 1999; Cappelli and Newmark, 2001; Huselid, 1995; Ichniowski et al., 1997; MacDuffie, 1995). These studies measure labour productivity as either the number of working hours required to produce a specific output (e.g. a ton of steel at a mini-mill or a vehicle at an assembly plant) or the value of sales per employee. The practices in question are those that allow organisations to elicit their employees' discretionary effort through the exploitation of the three conditions advocated by the AMO paradigm (Appelbaum et al., 2000): workers' ability (A) is ensured through the selection or initial training of employees with high skills or formal education and allows the deployment of a large stock of human capital; workers' motivation (M) is achieved through the provision of incentives such as investments in further training, employment security and trustenhancing systems of performance management (e.g. performance-related pay and internal promotions); working arrangements like self-managed teams and off-line problem-solving groups can provide workers with the opportunity $(\mathrm{O})$ to influence the decision-making process of the organisation and allow them to share their task-specific knowledge.

As yet, few company-level studies on the association between HRM practices and workplace productivity are available for Britain. Furthermore, most of these studies base their assessment on subjective measures of labour productivity. For example, using data from the WERS 1998, which includes 2,191 establishments from different sectors with 10 or more employees, Bryson et al. (2005) find a positive impact of bundles of 9 HRM practices on subjective measures of labour productivity for unionised workplaces. ${ }^{1}$ Guest and Hoque (1994) use a dataset of 122 non-unionised workplaces with 50 or more employees to explore the association between counts of $21 \mathrm{HRM}$ practices and subjective measures of labour

1 The self-assessed measures of labour productivity reported in the Cross-Section Management Questionnaire of the WERS indicate whether managers perceive their establishment's labour productivity as much higher, higher, the same, lower or much lower than the average labour productivity of their industry. 
productivity (compared to the best UK performers in the sector). They find that workplaces adopting a number of practices higher then the median enjoy higher productivity. Using a sample of 209 hotels with 25 or more employees, Hoque (1999) also finds a positive association between the number of practices in place (among 21) and subjective measures of labour productivity. Wood and de Menezes (1998) use a nationally representative sample of 899 workplaces in the private sector with 25 or more employees. The authors use a latent class analysis of seven practices to retrieve four categories of 'high commitment' practices (based on the extent of the adoption) and find that only workplaces in the third category, i.e. medium/high adoption, enjoy higher self-reported labour productivity.

Only few studies have explored the HRM-performance nexus in UK organisations relying on objective measures of productivity. Patterson et al. (1997) analyse the change in sales per employee for 67 single-site UK companies with 60 or more employees in the manufacturing sector using factor scores of HRM practices and find a positive association. Guest et al. (2003) use cross-section and panel data for 366 UK manufacturing and service companies with more than 50 employees. They find a positive relationship between an index of 48 HRM practices and subjective measures of labour productivity. However, this relationship disappears when objective productivity measures (sales per employee) are employed.

The extent to which subjective and objective measures of labour productivity converge is still an issue subject to debate (Forth and McNabb, 2008; Machin and Stewart, 1996; Wall et al., 2004). Nonetheless, the lack of availability of objective measures of productivity is generally regarded as a weak point of the UK-based empirical research on the HRMproductivity nexus.

\section{3 - HRM practices and knowledge sharing}

As explained above, the concept of knowledge is central to the AMO paradigm. Importantly, 'eliciting discretionary efforts from employees,' an expression often used by the advocates of the latter in reference to high-performance HRM practices, can broadly be considered as equivalent to 'eliciting employees' knowledge. ${ }^{2}$ However, this point has been rather neglected by the theoretical HRM literature, with the consequence that the same HRM practices, rather than employees' knowledge, are generally viewed as the resources to be combined to achieve competitive advantage. From an empirical point of view, this lack of attention to the knowledge construct has been exacerbated by the widespread use of aggregate HRM indexes, which do not permit to disentangle the performance contribution of HRM practices enhancing employees' knowledge disclosure from that of other organisational arrangements or processes.

In order to study the per se contribution of employees' knowledge to workplace productivity it is then crucial to clearly identify those HRM practices that bear implications for knowledge disclosure and keep them conceptually separated from other HRM practices. An attempt in this sense has been made by some studies on intra-organisational communication and information sharing. Bryson et al. (2006), for example, explore the

\footnotetext{
${ }^{2}$ Obviously, in some instances, the effort elicited from employees does not refer to their knowledge. Motivating the workforce, for example, may lead them to work longer hours rather than disclose information.
} 
association between subjective measures of workplace productivity and 'voice practices,' where the latter category includes "any formal mechanism by which workers can communicate their views to managements (Bryson et al., 2006: 439)." However, from the viewpoint of this paper, a general concern about their study is that HRM practices with opportunities for two-way communication like meetings of managers and employees and problem-solving groups of non-managerial employees are considered as having the same importance as one-way communication practices like formal surveys of employees' views/opinions and suggestion schemes. Furthermore, a two-way communication practice like teams is not included in the 'voice' category. Pertinently, Peccei et al. (2005) highlight that existing studies "do not, by and large, make a clear distinction ... between the various communication mechanisms that are used in organisations and the actual content of the information that is disclosed to employees (Peccei et al., 2005: 13)." Peccei et al. (2005) address this concern by studying the association between subjective measures of productivity and downward communication, that is, information disclosure from managers to employees of information relating to internal investment plans, staffing plans and the financial position of the workplace. While the authors consider a well-defined channel of information disclosure, the latter simply entails unidirectional knowledge flows. As previously argued, these flows are not those with the highest potential for competitive advantage.

In this paper we explicitly focus on FTFC as the means through which knowledge is shared among employees. It is important to clarify that the term 'knowledge sharing' is used throughout the paper to indicate a process of knowledge exchange where each individual involved is at the same time knowledge sender and receiver. Knowledge sharing is therefore conceptually different from knowledge transfer.

We consider five HRM practices that potentially imply FTFC. Specifically, we view problem-solving groups of non-managerial employees and teams of core employees as HRM practices enhancing workplace communities within which workers can share their tacit knowledge. Meetings of senior managers and employees and joint committees of managers and employees' representatives are also considered, with the acknowledgement that in this case the assumption that FTFC results in tacit knowledge sharing may be less realistic, considered the limited time spent by individuals within these networks compared to problemsolving groups and teams, and given the low level of personalisation of human interactions characterising them. Finally, we include meetings of line managers and employees. According to the WERS 2004, the survey on which this paper draws the data, line managers (or foremen) are non-managerial employees that have duties involving the supervision of other employees. The possibility that tacit knowledge is shared within this network is higher compared to meetings of senior managers and employees, since the working relationship established among peer workers is more likely to be characterised by a higher degree of personalisation. However, what is important to stress here is that, regardless of what type of knowledge is actually disclosed within the five networks considered, when such networks entail physical proximity and verbal interaction among employees they will provide a better context for knowledge to be shared.

Throughout the paper, we attempt to distinguish between the actual presence of FTFC

3 On ‘voice practices' see also Kersley et al. (2006) and Marchington (2007). 
within the five networks (in which case we speak of effective FTFC practices) and instances where individuals within such networks do not engage in FTFC (in which case we refer to these as merely formal FTFC practices). ${ }^{4}$ When we refer to the five HRM practices without specifying whether FTFC is actually present (the general approach adopted by the existing HRM literature) we shall call them potential FTFC practices.

Finally, this paper considers the time length for which FTFC practices are in place and their frequency. It is argued, in fact, that for the transfer of tacit knowledge to take place a high number of knowledge exchanges among individuals is required (Szulanski, 1996).

\section{DATA DESCRIPTION}

\section{1 - Productivity measures}

The dependent variable in our regression analysis is value added (in thousands of pounds) per employee. This measure of labour productivity is drawn from a dataset, provided by the Micro-data Analysis User Support team at the Office for National Statistics in London, which results from the merging of the WERS 2004 Financial Performance Questionnaire and the Annual Business Inquiry. After the exclusion of outliers, value added per employee is available for 570 of the trading workplaces included in the WERS 2004 Cross-Section Survey of Managers (see Forth and McNabb, 2007). It is important to note that while the inclusion of account-based measures of labour productivity strongly reduces the size of the sample of trading workplaces, it nevertheless permits to overcome the historical criticism attracted by the subjective assessment by managers of their workplace's labour productivity relative to other establishments in the same industry. ${ }^{5}$

\section{2 - HRM practices capturing knowledge sharing through FTFC}

Our independent variables are selected HRM practices potentially enhancing FTFC. The source of data on these is the WERS 2004 Cross-Section Survey of Managers, a nationally representative survey which includes detailed information, provided by managers responsible for employment relations matters, on a large number of HRM practices for 2,295 private and public UK workplaces with 5 or more employees. We limit our study to workplaces in the trading sector because data on objective measures of labour productivity are available only

\footnotetext{
${ }^{4}$ The need to identify effective FTFC communities, as opposed to merely formal ones, arises from the awareness that some HRM practices represent a missed opportunity to enhance knowledge sharing among individuals. For example, the members of a team may not exchange their knowledge in organisations dominated by the activity of the so-called 'knowledge workers,' who tend to develop their networks with external institutions rather than with co-workers within the firm (Swart, 2007). In this case the team arrangement (a potential FTFC community) gives raise to a merely formal FTFC community, which limits productivity gains for the organisation.

${ }^{5}$ Forth and $\mathrm{McNabb}$ (2008) analyse the extent to which subjective measures of productivity reported in the WERS 2004 and objective measures obtained after linking the Financial Performance Questionnaire with the Annual Business Inquiry converge.
} 
for a subset of trading workplaces, due to the interest in studying organisations with a profitmaximising behaviour. Our analysis focuses on the following HRM practices:

- Teams. The Survey of Managers reports the proportion (0, 1-19, 20-39, 40-59, 60$79,80-99$ or 100 per cent) of core employees working in formally-designated teams at each workplace. ${ }^{6}$

- Problem-solving (PS) groups. These are groups of non-managerial employees that solve specific problems or discuss aspects of performance or quality. Managers provided the proportion (coded as for teams) of workplace employees involved in such groups over the past year.

- Briefings. These are meetings between line managers and employees.

- Meetings. These are meetings between senior managers and employees.

- Committees. These are joint committees made up of managers and employees' representatives, and are mainly concerned with consultation.

Table 1 shows the percentage of trading workplaces adopting each of these arrangements as either potential or effective FTFC practices. These percentages are obtained based on the sub-sample of trading workplaces for which objective measures of labour productivity are available, and for which all the variables in question are non-missing. Nonetheless, figures are weighted in order to be made representative of the whole population of trading workplaces (see Forth and McNabb, 2007). We consider teams and PS groups as adopted if they involve any percentage of employees at the workplace or, alternatively, if they involve at least 60 per cent of employees.

Effective FTFC practices are those practices identifying employees' networks actually relying on FTFC. We try to capture the presence of FTFC using specific pieces of information provided in the WERS 2004 Cross-Section Survey of Managers. Specifically, teams are defined as effective FTFC practices if their members jointly decide how the work is to be done. Meetings and briefings entail FTFC if at least $25 \%$ of the time is available to employees to ask questions or offer their view. By their nature, PS groups and committees are arrangements aimed at enhancing FTFC among individuals and therefore they already identify effective FTFC practices. This explains why, in the table, these two arrangements show exactly the same percentages for potential and effective practices. We can see that the percentage of workplaces adopting effective FTFC practices is largely (always more than one third) lower than the percentage of workplaces adopting potential FTFC practices.

Table 2 reports the average value of our productivity measure across the five practices in question, again distinguishing between potential and effective FTFC practices. Additionally,

\footnotetext{
${ }^{6}$ Core employees are employees belonging to the largest non-managerial occupational group among those listed in the Standard of Occupational Classification (SOC) 2000.
} 
TABLE 1

Descriptive statistics for the adoption of FTFC practies

\begin{tabular}{lcc}
\hline & $\begin{array}{c}\text { Potential } \\
\text { FTFC practices }\end{array}$ & $\begin{array}{c}\text { Effective } \\
\text { FTF practices } \\
\end{array}$ \\
Mean (s.e.) & Mean (s.e.) \\
\hline Teams (any percentage of core employees) & $56 \%(4.0 \%)$ & $35 \%(3.7 \%)$ \\
Teams (at least 60\% of core employees) & $45 \%(3.9 \%)$ & $29 \%(3.6 \%)$ \\
PS groups (any percentage of non-manage rial employees) & $14 \%(2.4 \%)$ & $14 \%(2.4 \%)$ \\
PS groups (at least 60\% of non-managerial employees) & $6 \%(1.9 \%)$ & $6 \%(1.9 \%)$ \\
Meetings & $71 \%(3.6 \%)$ & $40 \%(3.9 \%)$ \\
Briefings & $56 \%(4.0 \%)$ & $32 \%(3.6 \%)$ \\
Committees & $10 \%(1.9 \%)$ & $10 \%(1.9 \%)$ \\
\hline
\end{tabular}

Notes: Figures are weighted to make them representative of the population of trading workplaces with 5 or more employees. They are based on 545 observations. Standard errors (s.e.) in parentheses.

mean values for workplaces which do not adopt these practices at all are reported. We notice that, with the exception of committees, value-added per employees is always higher for workplaces adopting any of the five arrangements (second column) compared to the case of non-adoption (first column). Considering the practices in the presence of FTFC (third column), we can see that workplaces adopting meetings and briefing with FTFC outperform workplaces adopting the same practices regardless of whether FTFC is present. On the contrary, labour productivity is lower in the case of teams with FTFC compared to teams adopted as a potential FTFC practice. However, this result may be driven by the existence of FTFC-related benefits that depend on the relative size of the networks (i.e. percentage of employees involved). The paper will also explores this issue.

TABLE 2

Comparison of value-added per employee across FTFC practices

\begin{tabular}{lccc}
\hline & \multicolumn{2}{c}{ Potential FTFC practices } & Effective \\
& No adoption & Adoption & FTFC practices \\
& Mean (s.e.) & Mean (s.e.) & Mean (s.e.) \\
\hline Teams (any percentage of core employees) & $4.609(0.033)$ & $4.629(0.033)$ & $4.625(0.047)$ \\
Teams (at least 60 \% of core employees) & $4.602(0.028)$ & $4.643(0.039)$ & $4.630(0.055)$ \\
PS) groups (any percentage of non-managerial employees) & $4.623(0.026)$ & $4.608(0.037)$ & $4.608(0.037)$ \\
PS groups (at least 60 \% of non-managerial employees) & $4.619(0.025)$ & $4.651(0.056)$ & $4.651(0.056)$ \\
Meetings & $4.581(0.038)$ & $4.636(0.029)$ & $4.646(0.037)$ \\
Briefings & $4.545(0.026)$ & $4.674(0.033)$ & $4.680(0.047)$ \\
Committees & $4.615(0.024)$ & $4.591(0.047)$ & $4.591(0.047)$ \\
\hline
\end{tabular}

Notes: Figures are weighted to make them representative of the population of trading workplaces with 5 or more employees.

Value-added per employee is expressed in logarithms. Standard errors (s.e.) in parentheses. 


\section{3 - Workplace, organisation and market controls}

In our regressions we also control for the workplace characteristics of size (logarithm of the number of employees), age (dummy for workplaces more than 20 years old) and trade union recognition (dummy variable). The organisation characteristics of size (dummy for organisations with more than 1000 employees) and foreign ownership (dummy for workplaces belonging to an organisation which is at least 50 per cent foreign-owned) are also included. Finally, we control for the degree of competition in the market (represented by the management informant's assessment on a 1-to-5 scale, where 1 is very low and 5 very high) and the industrial sector (11 dummies at the SIC 2003 section level).

\section{4 - Other HRM controls}

Finally, we control for the presence of the following HRM practices, that we group in two categories:

1)

HRM practices enhancing the deployment and development of a skilled workforce: ${ }^{7}$

- Skilled workforce ( 1 if 50 per cent or more of employees are professionals, associate professionals or technical employees and 0 otherwise).

- Off-the-job training ( 1 if at least 60 per cent of experienced core employees have been given time off their work in the last year to receive training and 0 otherwise).

- Induction programme (1 if an induction programme for new core employees exists and 0 otherwise).

- Recruitment test (1 if a personality or performance test is used for recruitment purposes and 0 otherwise).

- Performance appraisal (1 if it applies to at least 60 per cent of non-managerial employees and 0 otherwise).

- Multiskilling ( 1 if at least 60 per cent of core employees are formally trained to do jobs other than their own and 0 otherwise).

\footnotetext{
${ }^{7}$ A schooling variable and a skill indicator for core employees have been built with the purpose of controlling for human capital differences among workplaces. The "schooling attainment" variable was obtained by giving a score to each employee based on the highest academic qualifications reported in the Survey of Employees Questionnaire of the WERS 2004. After ranking the maximum academic attainments on a 6-point scale, we calculated the median for core employees in each workplace. The skills variable was obtained in a similar way based on the number of years that employees spent at the workplace, which the SEQ ranks from 1 to 5 . However, these two indicators have not been used alongside with the additional HRM controls since their inclusion reduced the number of observations to only around 370 workplaces.
} 
According to the AMO paradigm, the above HRM practices reflect the level of human capital (i.e., employees' ability) available to the organisation. Therefore, they allow us to control for differences among workplaces in the endowment of knowledge that can potentially be shared among employees through FTFC-based networks.

2) HRM practices providing employees with trust and motivation:

- Employment security (100 minus the percentage of employees, among those in the payroll during the past year, who stopped working at the workplaces because dismissed).

- Internal recruitment (1 if, when filling vacancies, internal applicants are the only sources or, other things equal, they are preferred to external applicants and 0 otherwise).

- Performance-related pay (1 if employees are paid based on result/merit pay or receive profit-related payments or bonuses and 0 otherwise).

- Core employees' autonomy (scale composed of three items: discretion, control over the pace and involvement in decisions over their work; Cronbach's alpha is $0.72)$.

- Information disclosure (scale composed of three items: disclosure by managers to employees of information relative to internal investment plans, financial position of the workplace and financial position of the organisation; Cronbach's alpha is $0.71)$.

Motivating workers through organisational commitment in order for them to share their knowledge is in fact considered a key issue for the successful management of knowledge (Hislop, 2003).

Taking account of non-missing observations on the HRM practices reflecting FTFC, the productivity measures, the workplace, organisation and market characteristics, and the other HRM controls we end up with a dataset including a number of workplaces slightly higher than 500. The actual size varies according to what variables we are considering in any specific regression.

\section{EMPIRICAL RESULTS}

Our empirical analysis first assesses whether the adoption by workplaces of teams, problemsolving groups, meetings between line/senior managers and employees and joint consultative committees, i.e. HRM practices identifying potential FTFC communities is positively related 
to labour productivity. Subsequently, we explore whether there is a positive productivity differential between effective and merely formal FTFC communities. A finding in this sense would suggest that it is FTFC that matters for productivity enhancements rather than HRM practices per se, and that previous studies may have failed to capture the important contribution that knowledge shared through this means bears for workplace productivity. Finally, we investigate whether the association between FTFC and productivity changes

TABLE 3

The association between FTFC practices and labour productivity

\begin{tabular}{|c|c|c|}
\hline Variables & $\begin{array}{l}\text { Regression } 1.1 \\
\text { Coeff. (std. err.) }\end{array}$ & $\begin{array}{l}\text { Regression } 1.2 \\
\text { Coeff. (std. err.) }\end{array}$ \\
\hline $\begin{array}{l}\text { PS groups }(1-19 \%) \\
\text { PS groups }(20-39 \%) \\
\text { PS groups }(40-59 \%) \\
\text { PS groups }(60-79 \%) \\
\text { PS groups }(80-99 \%) \\
\text { PS groups }(100 \%)\end{array}$ & $\begin{array}{l}-0.062(0.070) \\
-0.117(0.058)^{\star \star} \\
-0.022(0.073) \\
0.155(0.143) \\
0.028(0.099) \\
-0.108(0.073)\end{array}$ & $\begin{array}{l}-0.082(0.071) \\
-0.118(0.056)^{* *} \\
-0.008(0.074) \\
0.154(0.131) \\
0.036(0.095) \\
-0.096(0.077)\end{array}$ \\
\hline $\begin{array}{l}\text { Teams }(1-19 \%) \\
\text { Teams }(20-39 \%) \\
\text { Teams }(40-59 \%) \\
\text { Teams }(60-79 \%) \\
\text { Teams }(80-99 \%) \\
\text { Teams }(100 \%)\end{array}$ & $\begin{array}{r}0.032(0.069 \\
-0.008(0.062) \\
-0.033(0.114) \\
0.004(0.057) \\
-0.028(0.045) \\
0.050(0.043)\end{array}$ & $\begin{array}{l}-0.015(0.073) \\
0.058(0.105) \\
-0.200(0.090)^{* *} \\
-0.031(0.129) \\
0.022(0.056) \\
-0.002(0.061)\end{array}$ \\
\hline $\begin{array}{l}\text { Teams }(1-19 \%) \text { with FTFC } \\
\text { Teams }(20-39 \%) \text { with FTFC } \\
\text { Teams }(40-59 \%) \text { with FTFC } \\
\text { Teams }(60-79 \%) \text { with FTFC } \\
\text { Teams }(80-99 \%) \text { with FTFC } \\
\text { Teams }(100 \%) \text { with FTFC }\end{array}$ & & $\begin{array}{c}0.122(0.142) \\
-0.119(0.112) \\
0.454(0.194)^{\star *} \\
0.020(0.134) \\
-0.076(0.070) \\
0.060(0.077)\end{array}$ \\
\hline $\begin{array}{l}\text { Meetings } \\
\text { Meetings with FTFC }\end{array}$ & $-0.046(0.036)$ & $\begin{array}{c}-0.059(0.045) \\
0.023(0.043)\end{array}$ \\
\hline $\begin{array}{l}\text { Briefings } \\
\text { Briefings with FTFC }\end{array}$ & $0.040(0.032)$ & $\begin{array}{l}0.010(0.045) \\
0.021(0.048)\end{array}$ \\
\hline Committees & $0.038(0.046)$ & $0.031(0.040)$ \\
\hline $\begin{array}{l}\text { R-squared } \\
\text { Number of observations }\end{array}$ & $\begin{array}{l}0.449 \\
523\end{array}$ & $\begin{array}{l}0.450 \\
514\end{array}$ \\
\hline
\end{tabular}

Notes: Standard errors (in parentheses) are adjusted to account for the complex survey design in the 2004 WERS. All the variables listed in Section 3 are controlled for.

**: significant at the $5 \%$ level.

according to the intensity of adoption of FTFC.

Table 3 presents the results of the productivity regressions obtained when FTFC practices are considered as implemented regardless of the length of time for which they are actually in place. In Regression 1.1 we report the coefficients and standard errors for the dummy 
variables capturing potential FTFC practices. Specifically, for teams and problem-solving (PS) groups, a dummy variable is included for each category representing the percentage of employees involved. The excluded category is workplaces with no teams (or PS groups) at all. The sign of the coefficients for PS groups and teams varies according to the percentage of employees involved. Those for briefings and committees are positive, while the coefficient for meetings is negative. However, among all these only the (negative) coefficient for PS groups with 20 to 39 per cent of non-managerial employees is statistically significant (5\% level).

The absence of any significant coefficients might be attributable to the simple consideration of potential FTFC practices whereby no distinction is made between workplaces that actually implement FTFC and workplaces which do not. In Regression 1.2 we attempt to distinguish between merely formal and effective FTFC practices. Alongside with the coefficients and standard errors for each dummy variable identifying the potential FTFC practice, we report the coefficients and standard errors for another dummy variable identifying the effective FTFC. As explained before, for PS groups and committees potential and effective FTFC coincide, so the same dummies used in 1.1 are re-included. Basically, the coefficient on each of the additional dummies captures the productivity gain associated with FTFC within the network considered. The coefficients for the dummies on the potential FTFC practices in Regression 1.2 have a different meaning from those in Regression 1.1: here they capture the association of productivity with the same networks but in the absence of FTFC (i.e., merely formal FTFC practice).

We can see that the coefficients on 'Teams (40-59\%)' and 'Teams (40-59\%) with FTFC' are -0.200 and 0.454 , respectively (both significant at the $5 \%$ level). This suggests that teams involving this percentage of employees where FTFC is absent make a negative contribution to workplace productivity, while FTFC strongly increases their productivity. Summing up the two coefficients we obtain the association between labour productivity and Teams (40-59\%) adopted as an effective FTFC practice. The negative association between productivity and PS groups with 20 to 39 per cent of non-managerial employees is still negative and significant (5\% level). Finally, the coefficients on the remaining variables are not significant.

We now assess whether the association between FTFC and productivity changes if the five practices are implemented on a continuous basis. PS groups are considered permanent if they are adopted 'permanently' as opposed to 'for a fixed period of time' or 'a mixture of both.' There is no direct information in WERS 2004 on the permanency of teams, meetings and briefings. We consider briefings and meetings as permanent if they are conducted at least once a fortnight (unfortunately, there is no such information for teams). Finally, we consider committees as permanent if they are reported to be 'permanent' as opposed to 'temporary.' Table 4 shows the results of the regressions analysis carried out on FTFC practices which we considered as adopted permanently based on this information. In Regression 2.1 we show the association between potential FTFC practices and productivity. The coefficient on PS groups involving 20 to $39 \%$ of non-managerial employees presents a negative sign while that on briefings is positive (both coefficients are significant at the $1 \%$ level). All the other coefficients are not significant. Regression 2.2 shows instead the results obtained when we allow for FTFC to take place in the five networks in question. The coefficients on PS groups 
involving 20 to $39 \%$ of non-managerial employees, those including 60 to $79 \%$ of nonmanagerial employees and those including all non-managerial employees present a negative, positive and negative sign (significant at the $1 \%, 10 \%$ and $10 \%$ level, respectively). There is again a difference in sign between the coefficient on teams with 40 to $59 \%$ of core employees and the coefficient on the dummy variable capturing

TABLE 4

The association between permanent FTFC practices and labour productivity

\begin{tabular}{|c|c|c|}
\hline & $\begin{array}{l}\text { Regression } 2.1 \\
\text { Coeff. (std. err.) }\end{array}$ & $\begin{array}{l}\text { Regression } 2.2 \\
\text { Coeff. (std. err.) }\end{array}$ \\
\hline PS groups (1-19\%) & $-0.003(0.124)$ & $-0.049(0.140)$ \\
\hline PS groups (20-39\%) & $-0.331(0.093)^{* * *}$ & $-0.329(0.087)^{\star * *}$ \\
\hline PS groups (40-59\%) & $-0.023(0.090)$ & $-0.028(0.084)$ \\
\hline PS groups $(60-79 \%)$ & $0.123(0.129)$ & $0.274(0.150)^{*}$ \\
\hline PS groups $(80-99 \%)$ & $-0.071(0.124)$ & $-0.102(0.12)$ \\
\hline PS groups $(100 \%)$ & $-0.136(0.070)$ & $-0.136(0.076)^{*}$ \\
\hline Teams $(1-19 \%)$ & $0.045(0.073)$ & $0.014(0.068)$ \\
\hline Teams $(20-39 \%)$ & $0.002(0.052)$ & $0.116(0.100)$ \\
\hline Teams (40-59\%) & $-0.038(0.110)$ & $-0.242(0.077)^{\star * *}$ \\
\hline Teams $(60-79 \%)$ & $-0.024(0.053)$ & $-0.026(0.109)$ \\
\hline Teams $(80-99 \%)$ & $-0.014(0.049)$ & $0.003(0.064)$ \\
\hline Teams $(100 \%)$ & $0.055(0.042)$ & $0.007(0.057)$ \\
\hline Teams $(1-19 \%)$ with FTFC & & $0.075(0.147)$ \\
\hline Teams $(20-39 \%)$ with FTFC & & $-0.165(0.103)$ \\
\hline Teams $(40-59 \%)$ with FTFC & & $0.513(0.192)^{\star \star *}$ \\
\hline Teams $(60-79 \%)$ with FTFC & & $-0.026(0.114)$ \\
\hline Teams $(80-99 \%)$ with FTFC & & $-0.027(0.075)$ \\
\hline Teams $(100 \%)$ with FTFC & & $0.065(0.068)$ \\
\hline Meetings & $0.042(0.050)$ & $-0.042(0.060)$ \\
\hline Meetings with FTFC & & $0.185(0.083)^{\star *}$ \\
\hline Briefings & $0.114(0.038)^{* * *}$ & $0.035(0.047)$ \\
\hline Briefings with FTFC & & $0.114(0.057)^{\star \star}$ \\
\hline Committees & $0.067(0.045)$ & $0.053(0.044)$ \\
\hline R-squared & 0.475 & 0.517 \\
\hline Number of observations & 506 & 506 \\
\hline
\end{tabular}

Notes: Standard errors (in parentheses) are adjusted to account for the complex survey design in the 2004 WERS. All the variables listed in Section 3 are controlled for.

${ }^{* * *},{ }^{* *}, *$ : significant at the 1,5 and $10 \%$ level, respectively.

FTFC in the same teams. The absolute magnitude of the two coefficients is larger if compared to Table 1. Notably, the coefficient on briefings is now not significant, while the coefficient on 'Briefings with FTFC' is positive and significant ( $5 \%$ level). The coefficient 
on 'Meetings with FTFC' is also positive and significant (5\% level). Finally, there is a positive but not significant coefficient for committees.

We can draw some conclusion from the results presented above. First, the simple inclusion in the empirical analysis of potential FTFC practices (the approach generally adopted by the HRM literature) may have confounding effects: it can either lead to a failure to detect an association between some HRM practices and labour productivity (see, for example, the case of Teams (40-59\%)) or to a claim of unconditional positive association, when productivity gains are instead attributable to FTFC among members of the network (see, for example, the case of permanent briefings). Second, the relative size of (i.e., the percentage of employees involved in) FTFC-based networks seems to matters for productivity advantage. There is either no gain (for teams) or a negative association with productivity (for PS groups) for networks with too many or too few employees. However, the reasons behind this are still to be explored. Third, the tendency to adopt FTFC permanently is crucial to enhance organisational productivity. If adopted on a continuous basis, in fact, FTFC shows a positive and significant association with value added per worker within four of the five practices in question (the exception being committees). Notably, compared to a situation where the temporal dimension in the implementation of the FTFC practices is not considered, additional and positive productivity gains show up for problem-solving groups with 60 to 79 per cent of non-managerial employees, meetings and briefings, and the FTFC-related gain is higher for teams with 40 to 59 per cent of core employees. The simplest explanation of this result is that knowledge needs time to be shared, understood and processed in such a way as to produce observable gains to the organisation. An alternative explanation, drawn on the line of Bogenrieder and Nooteboom (2004), is that it may take time to build up trust and empathy between individuals, which is essential to an effective learning environment.

\section{CONCLUSIONS}

This paper uses cross-sectional data on around 500 British trading workplaces in order to investigate whether a positive productivity differential exists between workplaces that implement HRM practices in such a way as to enhance physical proximity and verbal interaction among employees (i.e., FTFC) and workplaces where such arrangements are not in place. Our assumption is that an intense process of knowledge sharing is more likely to arise in the former workplaces compared to the latter, and this should be reflected in higher productivity levels observable empirically.

We find indeed a positive association between value added per worker and FTFC in the social networks established through four HRM practices, namely problem-solving groups, teams, meetings of line managers and employees and meetings of senior managers and employees. Importantly, this finding holds provided that FTFC is adopted on a continuing basis. The simplest explanation of this result is that knowledge needs time to be shared, understood and processed in such a way as to produce observable gains to the organisation. An alternative explanation is that it might take time to build up trust and empathy between individuals, which is essential to an effective learning environment. We also find that the 
percentage of employees involved in FTFC-based networks is important to explain their association with labour productivity: discussion within teams results in productivity gains only if such arrangements entail 40 to 59 per cent of core employees, while for problemsolving groups 60 to 79 per cent of non-managerial employees must be involved. However, the reasons behind this finding are still to be explored. Our results are robust to the inclusion of other HRM practices that may indirectly provide employees with the ability and motivation to share their knowledge with each other.

As for the nature of the knowledge shared through FTFC-based networks, it is quite difficult to understand what type is actually disclosed within them. We recognise that in practice explicit and implicit knowledge may be used in combination. For example, workplaces adopting problem-solving groups or teams are expected to enjoy productivity benefits from both knowledge types exchanged by employees involved in such arrangements. Also, the positive association between productivity and FTFC found for some practices is not very likely to reflect gains form tacit knowledge sharing. In the case of meetings of senior managers and employees, for example, explicit knowledge is more likely to be transferred, which nonetheless has important implications for competitive advantage.

\section{REFERENCES}

Ambrosini, V. and Bowman, C. (2001), 'Tacit Knowledge: Some Suggestions for Operationalization,' Journal of Management Studies, 38(6): 811-829.

Appelbaum, E., Bailey, T., Berg, P., and Kalleberg, A. (2000), Manufacturing Advantage: Why High-Performance Systems Pay Off, Ithaca: ILR Press.

Arthur, J. (1994), 'Effects of human resource systems on manufacturing performance and turnover,' Academy of Management Journal, 37(3): 670-687.

Barney, J. B. (1991), Firm resources and sustained competitive advantage, Journal of Management, 17(1): 99-120.

Batt, R. (1999), 'Work organization, technology, and performance in customer service and sales,' Industrial and Labor Relations Review, 52(4): 539-564.

Bogenrieder, I. and Nooteboom, B. (2004), 'Learning groups: What types are there? A theoretical analysis and an empirical study in a consultancy firm,' Organization Studies, 25(2): 287-313

Bryson, A. Forth, J. and Kirby, S. (2005), 'High-involvement management practices, trade union representation and workplace performance in Britain,' Scottish Journal of Political Economy, 52(3): 451-491.

Bryson, A. Charlwood, A. and Forth, J. (2006), 'Worker voice, managerial response and labour productivity: an empirical investigation,' Industrial Relations Journal, 37(5): 438455.

Cappelli, P. and Neumark, D. (2001), 'Do 'High-Performance' Work Practices Improve Establishment-Level Outcomes?,' Industrial and Labor Relations Review, 54(4): 737-775. 
Delery, J. E. and Doty, D. H. (1996), 'Modes of theorizing in strategic human resources management: Tests of universalistic, contingency, and configurational performance predictions,' Academy of Management Journal, 39(4): 802-835.

Forth, J. and R. McNabb (2007), 'The Collection of Objective Data on Workplace Performance', in K. Whitfield and K. Huxley (eds), Innovations in the 2004 Workplace Employment Relations Survey (Cardiff, Cardiff University Press) pp. 84-118.

Forth, J. and R. McNabb (2008), 'Workplace Performance: A Comparison of Subjective and Objective Measures in the 2004 Workplace Employment Relations Survey,' Industrial Relations Journal, 39(2): 104-123.

Grant, R. M. (1993), 'Organizational capabilities within a knowledge-based view of the firm,' Paper presented at the Annual Meeting of the Academy of Management, Atlanta, Georgia.

Guest, D. and Hoque, K. (1994), 'The good, the bad and the ugly: employment relations in new non-union workplaces,' Human Resource Management Journal, 5(1): 1-14.

Guest, D., Michie, J., Conway, N. and Sheehan, M. (2003), 'Human resource management and corporate performance in the UK,' British Journal of Industrial Relations, 41(2): 291-314.

Hislop, D. (2003), 'Linking human resource management and knowledge management via commitment,' Employee Relations, 25(2): 182-202

Hoque, K. (1999), 'Human resource management and performance in the UK hotel industry,' British Journal of Industrial Relations, 37(3): 419-443.

Huselid, M. A. (1995), 'The impact of human resources management practices on turnover, productivity, and corporate financial performance,' Academy of Management Journal, 38(3): 635-672.

Ichniowski, C., Shaw, K. and Prennushi, G. (1997), 'The Effects of Human Resource Management Practices on Productivity: A Study of Steel Finishing Lines,' American Economic Review, 87(3): 291-313.

Jackson, S., Hitt, M. A. and DeNisi, A. S. (2003), Managing Knowledge for Sustained Competitive Advantage: Designing Strategies for Effective Human Resource Management. San Francisco: Jossey-Bass.

Kersley, B., Alpin, C., Forth, J., Bryson, A., Bewley, H., Dix, G. and Oxenbridge, S. (2006), Inside the Workplace: Findings from the 2004 Workplace Employment Relations Survey, London: Routledge.

Koskinen, K. U., Pihlanto, P. and Vanharanta, H. (2003), 'Tacit knowledge acquisition and sharing in a project work context,' International Journal of Project Management, 21: 281290.

Lepak, D. P. and Snell, S. A. (2007), 'Employment subsystems and HR architecture,' in Boxall, P., Purcell, J. and Wright, P. (Eds), The Oxford Handbook of Human Resource Management. Oxford University Press, 210-230.

MacDuffie, J. P. (1995), 'Human resource bundles and manufacturing performance: Organizational logic and flexible production systems in the world auto industry,' Industrial and Labor Relations Review, 48(2): 197-221.

Machin, S. and Stewart, M. (1996), 'Trade Unions and Financial Performance,' Oxford Economic Papers, 49: 213-241. 
Marchington, M. (2007), 'Employee voice systems,' in Boxall, P., Purcell, J. and Wright, P. (Eds), The Oxford Handbook of Human Resource Management. Oxford University Press, 231-250.

Meherabian, E. W. (1971), Silent messages. Belmont: Chandler.

Nahapiet, J. and Ghoshal, S. (1998), 'Social Capital, Intellectual Capital, and the Organizational Advantage,' Academy of Management Review, 23(2): 242-266.

Nonaka, I. (1991), 'The Knowledge-creating company,' Harvard Business Review, 69(6): 96104.

Nonaka, I. and Takeuchi, H. (1995), The Knowledge Creating Company: How Japanese Companies Create the Dynamics of Innovation, Oxford University Press, New York, NY.

Patterson, M., West, M., Lawthorn, R. and Nickell, S. (1997), Impact of People Management Practices on Business Performance, Issue in People Management No. 22, London: Institute of Personnel and Development.

Peccei, R., Bewley, H., Gospel, H. and Willman, P. (2005), 'Is It Good to Talk? Information Disclosure and Organizational Performance in the UK,' British Journal of Industrial Relations, 43(1): 11-39.

Polanyi, M. (1966), The Tacit Dimension, London: Routledge and Kegan Paul.

Rebernik, M. and Širec, K. (2007), 'Fostering innovation by unlearning tacit knowledge,' Kybernetes, 36(3/4): 406-419.

Sobol, M. G. and Lei, D. (1994), 'Environment, manufacturing technology and embedded knowledge,' International Journal of Human Factors in Manufacturing, 4(2): 167-189.

Spender, J.-C. (1993), 'Competitive advantage from tacit knowledge? Unpacking the concept and its strategic implication,' Best Paper Proceedings, Annual Meeting of the Academy of Management, Atlanta, Georgia.

Sternberg, R. J. (1994), 'Tacit knowledge and job success,' in Anderson, N. and Herriot, P. (Eds), Assessment and Selection in Organizations: Methods and Practice for Recruitment and Appraisal. London: John Wiley, 27-39.

Swart, J. (2007), 'HRM and knowledge workers,' in Boxall, P., Purcell, J. and Wright, P. (Eds), The Oxford Handbook of Human Resource Management. Oxford University Press, 450-468.

Szulanski, G. (1996), 'Exploring internal stickiness: impediments to transfer of best practice within the firm,' Strategic Management Journal, 17, Winter, special issue, 27-43.

Tsoukas, H. (1996), 'The Firm as a Distributed Knowledge System: a Constructionist Approach,' Strategic Management Journal, 17 (Winter Special Issue): 11-25.

Wall, T., Michie, J., Patterson, M., Wood, S., Sheehan, M., Clegg, C. W., and West, M. (2004), 'On the validity of subjective measures of company performance', Personnel

Psychology, 57: 95-118.

Wood, S. and de Menezes, L. (1998), 'High commitment management in the UK: evidence from the workplace industrial relations survey, and employers' manpower and skills practices survey,' Human Relations, 51(4): 485-515. 